\title{
EFEKTIFITAS FUNGI MIKORIZA ARBUSKULAR TERHADAP PERTUMBUHAN KIHIANG (Albizia procera Benth) DI PERSEMAIAN DAN LAPANGAN
}

\author{
Effectivity of Arbuscular Mycorrhizal Fungi on Plant Growth of \\ Albizia procera Benth in Nursery and Field
}

\author{
Ragil S.B. Irianto \\ Pusat Penelitian dan Pengembangan Hutan \\ Kampus Badan Litbang dan Inovasi, Jl. Gunung Batu No. 5, Kotak Pos 165, Bogor 16118, Jawa Barat, Indonesia \\ Telp. 0251-8633234; Fax. 0251-8638111 \\ Email:
}

Tanggal diterima: 14 April 2014; Tanggal direvisi: 30 Juli 2015; Tanggal disetujui: 11 Agustus 2015

\begin{abstract}
Albizia procera is a fast-growing species which have have benefits as its wood, bark and sap can be utilized. This study aimed to determine the effectiveness of for types Arbuscular Mycorrizal Fungi (AMF) namely Glomus sp. 1, Glomus sp. 2, Glomus sp. 3, and Gigaspora sp. on the growth of seedlings and young plants of A. procera. The results showed that the inoculation of AMF Glomus sp. 1 significantly increased the height and diameter growth of three month seedlings by $66 \%$ and $32 \%$ respectively compared to control. Mycorrhizal dependency of AMF Glomus $s p$. 1, Glomus sp. 2, Glomus sp. 3, and Gigaspora sp. range among 11-33\%. AMF Glomus sp. 2 and Glomus $s p .3$ increased significantly height and diameter growth of young plant in the field compared to control.
\end{abstract}

Keywords : Albizia procera, seedling, Gigaspora, Glomus, mycorrhizal dependency

\begin{abstract}
ABSTRAK
Albizia procera adalah jenis tanaman cepat tumbuh yang mempunyai beberapa manfaat, karena kayu, kulit kayu dan getahnya dapat dimanfaatkan. Tujuan dari penelitian ini adalah untuk mengetahui efektifitas empat jenis Fungi Mikoriza Arbuskular (FMA) yaitu Glomus sp. 1, Glomus sp. 2, Glomus sp. 3, dan Gigaspora sp. terhadap pertumbuhan bibit tanaman kihiang umur 3 bulan di persemaian dan tanaman muda umur 6 bulan di lapangan. Hasil penelitian menunjukkan bahwa inokulan FMA Glomus sp. 1 dapat meningkatkan pertumbuhan tinggi dan diameter bibit tanaman kihiang umur 3 bulan secara nyata sebesar $66 \%$ dan 32\% dibandingkan dengan kontrol. Tingkat ketergantungan bibit kihiang terhadap mikoriza Glomus sp. 1, Glomus sp. 2, Glomus sp. 3, dan Gigaspora sp. berkisar antara 11-33\%. Inokulan FMA Glomus sp. 2 dan Glomus sp. 3 dapat meningkatkan pertumbuhan tinggi dan diameter tanaman muda kihiang secara nyata terhadap kontrol.
\end{abstract}

Kata kunci: Albizia procera, bibit, Gigaspora, Glomus, ketergantungan bibit terhadap mikoriza

\section{PENDAHULUAN}

Albizia procera Benth (kihiang, weru, sinonim Acacia odoratissima Hask) adalah jenis tanaman cepat tumbuh yang termasuk dalam famili Leguminosae. Kihiang tumbuh pada hutan semusim hingga savana dengan ketinggian tempat tumbuh hingga $1.500 \mathrm{~m}$ dpl. Daerah sebaran alami kihiang di Indonesia terdapat di Jawa, Sumatera, Kalimantan, Sulawesi, Maluku, dan Nusa Tenggara (Whitmore \& Tantra, 1986). Kayu kihiang dapat digunakan sebagai kayu perkakas rumah tangga, bahan bangunan; kulit kayu untuk bahan penyamak; dan getahnya dimanfaatkan sebagai bahan perekat (Heyne, 1987).
Syamsuwida (2006) menyatakan bahwa kihiang merupakan jenis tanaman yang prospektif untuk dikembangkan sebagai jenis hutan rakyat karena potensinya sebagai jenis tanaman serbaguna (multi purpose tree species), cepat tumbuh dan jenis lokal yang disukai masyarakat sebagai tanaman kayu pertukangan. Untuk meningkatkan pertumbuhan awal tanaman perlu dilakukan perbaikan input hara tanaman baik melalui pemupukan maupun melalui inokulasi mikrob yang membantu pertumbuhan tanaman.

Lokasi persemaian dan penanaman kihiang umumnya dilakukan pada tanah podzolik merah kuning dengan ciri bereaksi masam, miskin unsur hara $\mathrm{N}, \mathrm{P}, \mathrm{K}$, lapisan top soil tipis dan memiliki 
kandungan bahan organik rendah (Setiadi, 1999). Pada tanah yang masam, unsur P biasanya terkhelat oleh Fe dan Al sehingga sulit diserap oleh akar tanaman. Oleh karena itu, bantuan simbiose Fungi Mikoriza Arbuskula (FMA) khelasi unsur $\mathrm{P}$ oleh ion-ion logam tersebut akan terlepas sehingga menjadi tersedia bagi akar tanaman (Setiadi, 1999). Aplikasi FMA dilakukan pada saat penyapihan (overspin) di persemaian dan akan membantu penyerapan unsur $\mathrm{P}$ dan unsur unsur lainnya seperti $\mathrm{N}$ dan $\mathrm{K}$ oleh bibit tanaman di persemaian (Wulandari et al., 2014; Neumann \& George, 2005; Kim et al., 2010; Huang et al., 2011; Bing et al., 2012; Halder et al., 2015).

Aplikasi teknologi mikrob tanah pada tanaman kihiang sampai saat ini baru ditemukan pada pemanfaatan rhizobia (Siddiqui, 1989). Sedangkan aplikasi mikrob menguntungkan lainnya seperti FMA belum pernah dilakukan ujicoba pada tanaman kihiang. Tanaman-tanaman kehutanan lainya juga berasosiasi dengan FMA antara lain yaitu Ploiarium alternifolium dan Calophyllum hosei (Turjaman et al., 2008), Mallotus paniculatus dan Albizia saman (Wulandari et al., 2014), Melia azedarach (Budi \& Setyaningsih, 2013), Aquilaria crassna (Irianto, 2015a), Alstonia angustiloba (Irianto, 2015b), Toona sureni (Irianto, 2015c), Alstonia scholaris (Irianto, 2009). Tujuan dari penelitian ini adalah untuk mengetahui efektifitas FMA jenis Glomus sp. 1, Glomus sp. 2, Glomus sp. 3, dan Gigaspora sp. terhadap pertumbuhan bibit tanaman kihiang di pesemaian dan tanaman muda di lapangan.

\section{METODOLOGI}

\section{A. Tempat dan Waktu Penelitian}

Penelitian dilaksanakan di persemaian Kelompok Peneliti Mikrobiologi Hutan, Pusat Litbang Konservasi dan Rehabilitasi, Bogor, pada bulan September sampai dengan Desember 2012. Penanaman bibit kihiang dilakukan di Kawasan Hutan Dengan Tujuan Khusus (KHDTK) Carita, Kecamatan Labuan, Kabupaten Pandeglang pada awal bulan Februari 2013. Penghitungan persentase kolonisasi dan proses pengeringan dan penimbangan berat kering dilaksanakan di Laboratorium Mikrobiologi Hutan.

\section{B. Bahan dan Alat}

Bahan-bahan yang digunakan dalam pelaksanaan penelitian ini adalah sebagai berikut: biji kihiang dari pohon induk di KHDTK Carita, 4 jenis FMA dalam bentuk propagul aktif yang mengandung miselia, akar terinfeksi dan spora. Setiap $5 \mathrm{~g}$ inokulan memiliki kepadatan spora berturut-turut Glomus sp. 1 (75 spora), Glomus sp. 2 (50 spora), Glomus sp. 3 (47 spora), dan Gigaspora sp. (52 spora). Bahan lain yang diperlukan adalah kantong plastik hitam (polybag, ukuran $10 \times 12 \mathrm{~cm}$ ), kantong plastik transparan (ukuran $100 \times 140 \mathrm{~cm}$ ), bak perkecambahan (ukuran $44 \times 24 \times 20 \mathrm{~cm}$ ), pestisida dengan bahan aktif dazomet $98 \%$, tanah subsoil pada kedalaman $20-40 \mathrm{~cm}$, dan paranet $60 \%$. Alat-alat yang digunakan dalam penelitian ini adalah kaliper, penggaris, mikroskop, kamera, embrat, dan timbangan analitik.

\section{Metode Penelitian}

\section{Sterilisasi media}

Media perkecambahan zeolit disterilisasikan dengan alat autoklaf pada suhu $121^{\circ} \mathrm{C}$ dan tekanan 1 atm selama 30 menit. Sedangkan sterilisasi media sapih bibit dilakukan melalui teknik fumigasi dengan cara setiap satu $\mathrm{m}^{3}$ media dicampur dengan $200 \mathrm{~g}$ pestisida dengan bahan aktif dazomet $98 \%$. Selanjutnya media diaduk secara merata dengan cangkul. Media tersebut kemudian ditutup secara rapat dengan plastik transparan selama dua minggu.

\section{Perkecambahan dan inokulasi}

Biji disebarkan secara merata pada media zeolit yang steril pada bak perkecambahan plastik, kemudian di atas biji ditaburi media zeolit setebal $3 \mathrm{~mm}$. Selanjutnya bak perkecambahan tersebut disimpan dalam persemaian yang diberi atap paranet dengan intensitas cahaya $60 \%$, kelembaban media dijaga dengan cara penyemprotan dengan air setiap pagi dan sore hari.

Setelah biji berkecambah selanjutnya dipindah ke dalam polybag yang telah diisi dengan campuran media tanah dan sekam padi steril $(19: 1 \mathrm{v} / \mathrm{v})$. Inokulan FMA diletakkan pada lubang tanam dalam polybag sebanyak $5 \mathrm{~g}$ setiap polybag.

\section{Penanaman bibit di lapang}

Lubang tanam $(30 \times 30 \times 30 \mathrm{~cm})$ dengan jarak tanam $3 \times 3 \mathrm{~m}$ dipersiapkan satu bulan sebelum penanaman, kemudian diisi dengan pupuk kandang ayam pedaging $2 \mathrm{~kg}$ dan dibiarkan sampai waktu penanaman. 


\section{Pengamatan pertumbuhan dan kolonisasi akar}

Variabel pertumbuhan bibit tanaman kihiang yang diamati yaitu tinggi, diameter $(1 \mathrm{~cm}$ di atas permukaan tanah), berat kering bibit (dioven selama 3 hari pada suhu $70^{\circ} \mathrm{C}$ sampai berat konstan), dan kolonisasi akar. Sedangkan variabel pertumbuhan tanaman di lapangan yang diamati adalah tinggi dan diameter $(5 \mathrm{~cm}$ di atas permukaan tanah).

Kolonisasi akar dihitung dengan merendam akar contoh dalam larutan $10 \% \mathrm{KOH}(\mathrm{w} / \mathrm{v})$, selanjutnya direndam dengan larutan $10 \% \mathrm{HCl}$. Setelah itu akar-akar tersebut direndam dalam larutan pewarna 0,05\% trypan blue. Persentase kolonisasi akar dihitung dengan metode Giovannetti \& Mosse (1980).

\section{Ketergantungan bibit terhadap mikoriza}

Ketergantungan bibit tanaman kihiang terhadap mikoriza (MD, Mycorrhizal Dependency) dihitung berdasarkan rumus yang dikemukakan oleh Plenchette et al. (1983):

$$
\mathrm{KBTM}=\frac{\mathrm{A}-\mathrm{B}}{\mathrm{A}} \times 100 \%
$$

Keterangan (Remarks):

$\mathrm{KBTM}=$ Ketergantungan bibit terhadap mikoriza

A $\quad=$ Berat kering tanaman bermikoriza

$\mathrm{B} \quad=$ Berat kering tanaman kontrol

\section{Rancangan penelitian dan analisis data}

Rancangan penelitian pembibitan di persemaian adalah Rancangan Acak Lengkap dengan lima perlakuan (kontrol, Glomus sp. 1, Glomus sp. 2, Glomus sp. 3 dan Gigaspora sp.), sedangkan rancangan penelitian yang digunakan pada saat penanaman di lapangan adalah Rancangan Acak Kelompok dengan lima perlakuan, jumlah ulangan tiga dan masing-masing ulangan terdiri dari 9 tanaman. Data dianalisis dengan bantuan program statistika JMP Start Statistics 10, dan data yang menunjukkan perbedaan nyata diuji lebih lanjut menggunakan uji Tukey (Sall et al., 2005).

\section{HASIL DAN PEMBAHASAN}

\section{A. Hasil}

\section{Pertumbuhan bibit kihiang di pesemaian}

Hasil analisis sidik ragam menunjukkan bahwa jenis FMA berpengaruh nyata terhadap pertumbuhan tinggi bibit kihiang dan Gigaspora sp. dapat meningkatkan pertumbuhan tinggi bibit secara nyata dibandingkan dengan kontrol, namun tidak meningkatkan pertumbuhan diameter bibit kecuali pada perlakuan inokulasi dengan inokulan FMA Glomus sp. 1. Persentase kolonisasi akar yang diinokulasi dengan Glomus sp. 1 dan Glomus sp. 3 berbeda nyata dengan kontrol (Tabel 1).

Tabel(Table) 1. Pengaruh inokulasi FMA terhadap pertumbuhan tinggi, diameter dan kolonisasi akar bibit tanaman kihiang umur 3 bulan di pesemaian (The effect of AMF inoculation to height, diameter plant growth and root colonization of three-month-old A. procera seedlings in nursery)

\begin{tabular}{|c|c|c|c|}
\hline $\begin{array}{l}\text { Jenis FMA } \\
\qquad(A M F)\end{array}$ & $\begin{array}{c}\text { Tinggi } \\
(\text { Height }) \\
(\mathrm{cm})\end{array}$ & $\begin{array}{c}\text { Diameter } \\
\text { (Diameter) } \\
(\mathrm{mm})\end{array}$ & $\begin{array}{c}\text { Kolonisasi akar } \\
(\text { Root colonization) }(\%)\end{array}$ \\
\hline Glomus sp. 1 & $\begin{array}{l}26,72 \mathrm{a} \\
(66)\end{array}$ & $\begin{array}{c}1,615 \mathrm{a} \\
(32)\end{array}$ & $\begin{array}{l}9 \mathrm{~b} \\
(22)\end{array}$ \\
\hline Glomus sp. 2 & $\begin{array}{l}25,28 \mathrm{ab} \\
(57)\end{array}$ & $\begin{array}{c}1,408 \mathrm{ab} \\
(15)\end{array}$ & $\begin{array}{c}17 \mathrm{ab} \\
(59)\end{array}$ \\
\hline Glomus sp. 3 & $\begin{array}{l}23,47 \mathrm{~b} \\
(46)\end{array}$ & $\begin{array}{c}1,362 \mathrm{~b} \\
(11)\end{array}$ & $\begin{array}{l}29 \mathrm{a} \\
(76)\end{array}$ \\
\hline Gigaspora sp. & $\begin{array}{c}24,56 \mathrm{~b} \\
(53)\end{array}$ & $\begin{array}{l}1,391 \mathrm{ab} \\
(13)\end{array}$ & $\begin{array}{c}24 \mathrm{ab} \\
(71)\end{array}$ \\
\hline Kontrol. & $\begin{array}{c}16,07 \mathrm{c} \\
(0)\end{array}$ & $\begin{array}{c}1,226 \mathrm{~b} \\
(0)\end{array}$ & $\begin{array}{l}7 \mathrm{~b} \\
(0)\end{array}$ \\
\hline
\end{tabular}

Sumber (Source): Diolah data lapang (Compiled and analyzed from field data)

Keterangan (Remarks):

1. Angka yang diikuti oleh huruf yang sama menunjukkan tidak ada perbedaan yang nyata pada taraf $\alpha=0,05$ berdasarkan uji Tukey (Numeric followed by the same letters are not significantly different at $\alpha<0.05$ according to Tukey test)

2. Angka dalam tanda kurung adalah persentase peningkatan suatu variabel pengamatan dibandingkan dengan kontrol (Numeric in the parenthesis is percentage of variable increment compared to the control) 


\section{Berat kering bibit $A$. procera}

Hasil analisis sidik ragam menunjukkan bahwa keempat jenis FMA tidak memberikan pengaruh yang nyata terhadap berat kering akar, pada berat kering pucuk semua perlakuan memberikan pengaruh nyata kecuali perlakuan Gigaspora sp. Sedangkan pada berat kering total bibit hanya perlakuan Glomus sp. 3 yang memberikan pengaruh yang nyata dibandingkan dengan kontrol (Tabel 2).

Rasio pucuk-akar bibit kihiang umur 3 bulan di pesemaian meningkat dengan adanya perlakuan inokulasi FMA dengan kisaran 22-38\% dibandingkan dengan kontrol (Tabel 2). Bibit kihiang yang mendapat perlakuan inokulasi FMA dapat meningkatkan tingkat ketergantungan bibit terhadap FMA yang berkisar anatar 11-33\% (Tabel 2).

\section{Penyerapan hara}

Hasil analisis sidik ragam menunjukkan bahwa jenis FMA Glomus sp. 1, Glomus sp. 2 dan Glomus sp. 3 memberikan pengaruh yang nyata terhadap serapan unsur $\mathrm{N}, \mathrm{P}$ dan $\mathrm{K}$ yang terdapat pada jaringan batang dan daun bibit $A$. procera kecuali perlakuan inokulasi Glomus sp. 2 pada parameter serapan unsur P. Perlakuan inokulasi jenis FMA Gigaspora sp. hanya memberikan perbedaan yang nyata pada parameter serapan unsur $\mathrm{P}$, sedangkan unsur $\mathrm{N}$ dan $\mathrm{K}$ tidak memberikan respon yang nyata (Tabel 3 ).

\section{Pertumbuhan tanaman muda $A$. procera di lapang}

Hasil analisis sidik ragam menunjukkan bahwa inokulasi FMA Glomus sp. 2, Glomus sp. 3, dan Gigaspora sp. dapat meningkatkan pertumbuhan tinggi dan diameter secara nyata dibandingkan dengan kontrol (inokulasi dilakukan pada saat overspin di pesemaian), kecuali perlakuan inokulasi Gigaspora sp. terhadap parameter pertumbuhan tinggi tanaman. Peningkatan pertumbuhan tinggi dan diameter berturutturut berkisar antara $19-27 \%$ dan $12-22 \%$ dibandingkan dengan kontrol.

\section{B. Pembahasan}

Perlakuan inokulasi keempat jenis FMAdapat meningkatkan pertumbuhan tinggi, diameter, dan biomas bibit tanaman kihiang umur 3 bulan di persemaian dengan cukup tajam dibandingkan dengan kontrol. Hal ini diduga karena adanya peningkatan kolonisasi akar pada bibit yang mendapat perlakuan inokulasi baik Glomus sp. 1, Glomus sp. 2, Glomus sp. 3, maupun Gigaspora sp. yang berkisar pada $22-79 \%$.

Tabel(Table) 2. Pengaruh inokulasi FMA terhadap berat kering akar, pucuk, total dan persentase ketergantungan bibit tanaman kihiangnumur 3 bulan terhadap FMA (The effect of AMF application to root dry weight, shoot dry weight, total dry weight, and mycorrhizal dependency of three-month-old Albizia procera)

\begin{tabular}{|c|c|c|c|c|c|}
\hline $\begin{array}{c}\text { Jenis FMA } \\
(A M F)\end{array}$ & $\begin{array}{c}\text { Berat Kering } \\
\text { Akar } \\
\text { (Root Dry } \\
\text { Weight }) \\
\text { g }\end{array}$ & $\begin{array}{c}\text { Berat Kering } \\
\text { Pucuk } \\
\text { (Shoot Dry } \\
\text { Weight) } \\
\text { g }\end{array}$ & $\begin{array}{l}\text { Berat Kering } \\
\text { Total } \\
\text { (Seedlings Dry } \\
\text { Weight) } \\
\text { g }\end{array}$ & $\begin{array}{c}\text { Rasio Pucuk } \\
\text { Akar } \\
\text { (Shoot Root } \\
\text { Ratio })\end{array}$ & $\begin{array}{c}\text { Ketergantungan } \\
\text { Bibit terhadap } \\
\text { Mikoriza } \\
\text { (Mycorrhizal } \\
\text { Dependency) } \\
\%\end{array}$ \\
\hline Glomus sp. 1 & $\begin{array}{c}0,5567 \mathrm{a} \\
(12)\end{array}$ & $\begin{array}{c}1,0714 \mathrm{a} \\
(52)\end{array}$ & $\begin{array}{c}1,6280 \mathrm{ab} \\
\text { (35) }\end{array}$ & $\begin{array}{l}1,9 \\
(26)\end{array}$ & 26 \\
\hline Glomus sp. 2 & $\begin{array}{c}0,5289 \mathrm{a} \\
(7)\end{array}$ & $\begin{array}{c}1,0955 \mathrm{a} \\
(55)\end{array}$ & $\begin{array}{c}1,6244 \mathrm{ab} \\
(35)\end{array}$ & $\begin{array}{l}2,0 \\
(33) \\
\end{array}$ & 26 \\
\hline Glomus sp. 3 & $\begin{array}{c}0,6298 \mathrm{a} \\
(27)\end{array}$ & $\begin{array}{c}1,1637 \mathrm{a} \\
(65)\end{array}$ & $\begin{array}{c}1,7935 \mathrm{a} \\
(49)\end{array}$ & $\begin{array}{l}1,8 \\
(22)\end{array}$ & 33 \\
\hline Gigaspora sp. & $\begin{array}{c}0,4267 \mathrm{a} \\
(-14)\end{array}$ & $\begin{array}{c}0,9248 \mathrm{ab} \\
(31)\end{array}$ & $\begin{array}{c}1,3515 \mathrm{~b} \\
(12)\end{array}$ & $\begin{array}{c}2,1 \\
(38) \\
\end{array}$ & 11 \\
\hline Kontrol & $\begin{array}{c}0,4953 \mathrm{a} \\
(0)\end{array}$ & $\begin{array}{c}0,7068 \mathrm{~b} \\
(0)\end{array}$ & $\begin{array}{c}1,2021 \mathrm{~b} \\
(0)\end{array}$ & $\begin{array}{l}1,4 \\
(0)\end{array}$ & 0 \\
\hline
\end{tabular}

Sumber (Source): Diolah data lapang (Compiled and analyzed from field data)

Keterangan (Remarks):

1. Angka yang diikuti oleh huruf yang sama menunjukkan tidak ada perbedaan yang nyata pada taraf $\alpha=0,05$ berdasarkan uji Tukey (Numeric followed by the same letters are not significantly different at $\alpha<0.05$ according to Tukey test)

2. Angka dalam tanda kurung adalah persentase peningkatan suatu variabel pengamatan dibandingkan dengan kontrol (Numeric in the parenthesis is percentage of variable increment compared to the control) 
Tabel (Table) 3. Pengaruh inokulasi FMA terhadap jumlah serapan unsur N, P, dan K pada bibit tanaman kihiang umur 3 bulan di pesemaian (The effect of $A M F$ inoculation to $N, P, K$ uptake of three-months-old Albizia procera seedlings in nursery)

\begin{tabular}{lccc}
\hline \multirow{2}{*}{$\begin{array}{c}\text { Jenis FMA } \\
(A M F)\end{array}$} & \multicolumn{4}{c}{$\begin{array}{c}\text { Serapan hara } \\
\text { (Nutrient upake }) \\
\text { mg/seedling }\end{array}$} \\
\cline { 2 - 4 } & $\mathrm{N}$ & $\mathrm{P}$ & $\mathrm{K}$ \\
\hline \multirow{2}{*}{ Glomus sp. 1} & $32,6687 \mathrm{a}$ & $2,9304 \mathrm{a}$ & $(63)$ \\
\hline \multirow{2}{*}{ Glomus sp. 2} & $(49)$ & $2,0035 \mathrm{bc}$ & $(62)$ \\
\hline \multirow{2}{*}{ Glomus sp. 3} & $31,5683 \mathrm{a}$ & $(11)$ & $19,2767 \mathrm{a}$ \\
& $(44)$ & $2,8097 \mathrm{a}$ & $(52)$ \\
\hline \multirow{2}{*}{ Gigaspora sp. } & $30,6681 \mathrm{a}$ & $(56)$ & $(60,7144 \mathrm{a}$ \\
\hline \multirow{2}{*}{ Kontrol } & $(40)$ & $2,5229 \mathrm{ab}$ & $(64)$ \\
& $25,3189 \mathrm{ab}$ & $(40)$ & $(29)$ \\
\hline
\end{tabular}

Sumber (Source): Diolah data lapang (Compiled and analyzed from field data)

Keterangan (Remarks):

1. Angka yang diikuti oleh huruf yang sama menunjukkan tidak ada perbedaan yang nyata pada taraf $\alpha=0,05$ berdasarkan uji Tukey (Numeric followed by the same letters are not significantly different at $\alpha<0.05$ according to Tukey test)

2. Angka dalam tanda kurung adalah persentase peningkatan suatu variabel pengamatan dibandingkan dengan kontrol (Numeric in the parenthesis is percentage of variable increment compared to the control)

Tabel(Table) 4. Pengaruh inokulasi FMA terhadap pertumbuhan tinggi dan diameter tanaman muda kihiang umur 6 bulan di lapang (The effect of AMF inoculation to height, diameter plant growth of six-months-old Albizia procera in the field)

\begin{tabular}{lcc}
\hline $\begin{array}{c}\text { Jenis FMA } \\
(A M F)\end{array}$ & $\begin{array}{c}\text { Tinggi } \\
(\text { Height })\end{array}$ & $\begin{array}{c}\text { Diameter } \\
\text { (Diameter }) \\
\text { cmm }\end{array}$ \\
\hline \multirow{2}{*}{ Glomus sp 1} & $53,13 \mathrm{ab}$ & $2,833 \mathrm{bc}$ \\
& $(10)$ & $(9)$ \\
\hline \multirow{2}{*}{ Glomus sp. 2} & $60,43 \mathrm{a}$ & $2,929 \mathrm{ab}$ \\
& $(25)$ & $2,912 \mathrm{ab}$ \\
Glomus sp3. & $61,47 \mathrm{a}$ & $(12)$ \\
\hline \multirow{2}{*}{ Gigaspora sp. } & $(27)$ & $3,156 \mathrm{a}$ \\
& $57,38 \mathrm{ab}$ & $(22)$ \\
\hline \multirow{2}{*}{ Kontrol } & $(19)$ & $2,593 \mathrm{c}$ \\
\end{tabular}

Sumber (Source): Diolah data lapang (Compiled and analyzed from field data)

Keterangan (Notes) :

1. Angka yang diikuti oleh huruf yang sama menunjukkan tidak ada perbedaan yang nyata pada taraf $\alpha=0,05$ berdasarkan uji Tukey (Numeric followed by the same letters are not significantly different at $\alpha<0.05$ according to Tukey test)

2. Angka dalam tanda kurung adalah persentase peningkatan suatu variabel pengamatan dibandingkan dengan kontrol (Numeric in the parenthesis is percentage of variable increment compared to the control)

Persentase kolonisasi akar adalah cerminan dari adanya hifa internal, vesikel dan vakuola dalam jaringan akar, hal ini akan meningkatkan jumlah hifa eksternal yang muncul pada akarakar bibit kihiang. Dengan semakin meningkatnya hifa eksternal tersebut yang merupakan kepanjangan dari akar bibit dan peningkatan biomas akar akan meningkatkan luasan daerah serapan menjadi lebih besar volumenya. Dengan semakin besarnya volume tanah yang dijadikan sebagai daerah serapan tersebut, maka peluang hifa-hifa eksternal untuk mengabsorbsi unsurunsur hara seperti unsur N, P, K dan air semakin besar dibandingkan dengan bibit tanaman tanpa bermikoriza (Fan et al., 2011; Khade \& Rodrigues, 2009; dan Turjaman et al., 2006).

Penelitian Jakobsen et al. (1992) menyatakan panjang hifa-hifa eksternal pada Tribolium subterraneum L. yang diinokulasi dengan Glomus sp. dan Scutellospora calospora dapat mencapai 
$32 \mathrm{~mm}, 31 \mathrm{~mm}$ dan $48 \mathrm{~mm}, 48 \mathrm{~mm}$ pada hari ke 28 dan 47 setelah perlakuan inokulasi, sedangkan panjang hifa eksternal pada akar T. subterraneum yang diinokulasi Glomus tenue dan Acaulospora laevis sebesar 3,929 dan $4,219 \mathrm{~cm} / \mathrm{g}$ soil pada kedalaman $5 \mathrm{~cm}$ dari permukaan tanah (Abbott \& Robson, 1985).

Peningkatan hara N, P dan K pada bibit yang bermikoriza tersebut sangat bermanfaat bagi pelaksana di persemaian dalam kegiatan produksi bibit dan penanaman di lapangan, khususnya penanaman pada lahan dan hutan yang kritis seperti pada program penghijauan yang dilakukan oleh Kementerian Kehutanan. Areal kritis yang menjadi prioritas penghijauan masih sangat cukup luas yaitu areal lahan dan hutan yang kritis seluas 22.025.581 ha dan sangat kritis seluas 5.269.260 ha (Kementerian Kehutanan, 2014). Sementara luas lahan hutan yang telah direhabilitasi pada tahun 2013 hanya seluas 119.095 ha dan jumlah tersebut sangat kecil $(0,4 \%)$ apabila dibandingkan dengan total luasan lahan dan hutan yang terdegradasi.

Keuntungan yang didapatkan para praktisi (pelaksana) penghijauan kehutanan di lapangan apabila menggunakan FMA pada produksi bibit di pesemaian adalah bibit tanaman bermikoriza lebih sehat dan kokoh, waktu pembibitan yang lebih singkat (Irianto, 2015a), bibit mempunyai daya adaptif yang tinggi untuk ditanam pada lahan marginal (Setiadi, 2009), tingkat ketahanan bibit/tanaman yang tinggi terhadap penyakit patogen tular tanah (Hage-Ahmed et al., 2013, Larsen et al., 2012, Ismail et al., 2013, Kobra et al., 2009), meningkatkan biomassa tanaman (Binu et al., 2015), serta mengurangi jumlah pupuk yang digunakan pada saat pembibitan maupun penanaman di lapang.

Rasio pucuk akar pada bibit yang mendapat perlakuan inokulasi FMA semakin meningkat sebesar 22-38\% dibandingkan dengan kontrol dikarenakan pertumbuhan pucuk yang lebih besar dibandingkan dengan akar (Tabel 2), hal ini sesuai dengan penelitian Fan et al. (2011) pada tanaman strawberi kultivar Jewel dan Saint-Pierre.

Tingkat ketergantungan tanaman terhadap mikoriza (KBTM, mycorrhizal dependency, MD) adalah perbandingan peningkatan pertumbuhan biomassa kering antara bibit tanaman yang bermikoriza dan bibit tanaman kontrol dengan bibit tanaman bermikoriza yang dinyatakan dalam bentuk persen (Plenchette et al., 1983). Nilai MD bibit tanaman kihiang terhadap FMA Glomus sp. 1, Glomus sp. 2, Glomus sp. 3 dan Gigaspora sp. adalah $26 \%, 26 \%, 33 \%$ dan $11 \%$. Berdasarkan klasifikasi tingkat ketergantungan tananaman terhadap FMA yang dikemukakan oleh Cruz et al. (1995) dibagi menjadi tiga kelas yaitu rendah $(0<10)$, sedang $(10-40)$ dan tinggi $(>40-100)$. Tingkat ketergantungan bibit tanam-an kihiang terhadap keempat inokulan FMA yang diaplikasikan pada saat overspin masuk dalam kategori sedang. Nilai sedang tersebut mengindikasikan bahwa perlakuan inokulasi pada bibit tanaman di pesemaian akan menguntungkan dalam produksi bibit, dan menjadi salah satu faktor pendukung tingkat keberhasilan bibit setelah ditanam di lapangan. Inokulasi akan membantu bibit tumbuh lebih baik, tahan terhadap kekeringan, tahan hidup pada tanah yang miskin unsur hara dan tahan terhadap infeksi penyakit, sehingga persentase tanaman hidup di lapangan akan lebih tinggi.

Pertumbuhan tinggi dan diameter tanaman muda $A$. procera umur 6 bulan di lapangan masih menunjukkan adanya respon inokulasi FMA Glomus sp. 2, dan Glomus sp. 3, yang nyata dibandingkan dengan kontrol (inokulasi dilakukan pada saat overspin di pesemaian). Peningkatan pertumbuhan tinggi dan diameter berturutturut berkisar antara $25-27 \%$ dan $12-13 \%$ dibandingkan dengan kontrol. Hasil penelitian ini sejalan dengan penelitian Irianto (2015b) pada tanaman muda pulai hitam umur 4 bulan di lapangan (pada saat di pembibitan diinokulasi dengan Glomus sp. 1 dan Glomus sp. 2) dengan peningkatan tinggi dan diameter sebesar $15 \%, 19 \%$ dan $8 \%$, $11 \%$, dan tanaman penghasil gaharu (Aquilaria crassna) umur 6 bulan (pada saat di pembibitan diinokulasi dengan Glomus sp. 1 dan Glomus sp. 2) dengan peningkatan tinggi dan diameter sebesar 67\%, 81\%, dan 66\%, $76 \%$ (Irianto, 2015a).

Penambahan bahan organik dalam bentuk pupuk kandang kotoran ayam seberat $2 \mathrm{~kg}$ per lubang $(2,2$ ton/ha) tidak mempengaruhi perkembangan FMA pada tanaman muda. Hal ini diperkuat oleh a) penelitian Valarini et al. (2009) yang memberikan kompos dengan dosis 8 ton/ha pada tanaman gandum yang masih menunjukkan peningkatan jumlah spora dan panjang miselium, dan b) pada tanaman yang diinokulasi dengan Glomus sp. 1, Glomus sp. 2 dan Glomus sp. 3 dan Gigaspora sp. masih menunjukkan peningkatan pertumbuhan tinggi tanaman berkisar antara 25$27 \%$ dan diameter sebesar $22 \%$.

FMA mengeluarkan enzim hidrolitik seperti selulose, pekninase dan xiloglukanase yang terlibat dalam mineralisasi bahan organik (AtulNayyar, 2009). Valarini (2009) menyatakan aplikasi FMA meningkatkan unsur hara, aerasi dalam tanah, agegrasi partikel tanah dan kapasitas me- 
nahan air (water holding capacity). Di samping itu, pemberian bahan organik juga akan meningkatkan pertumbuhan FMA akan lebih baik di dalam tanah (Gryndler et al., 2006).

\section{KESIMPULAN DAN SARAN}

\section{A. Kesimpulan}

Inokulan FMA Glomus sp. 1 Glomus sp. 2, Glomus sp. 3 dan Gigaspora sp. mampu mengkolonisasi bibit kihiang dengan tingkat ketergantungan terhadap mikoriza sedang. Dari keempat inokulan tersebut yang efektif secara nyata meningkatkan pertumbuhan tinggi, diameter bibit dan serapan hara di tingkat pesemaian adalah Glomus sp. 1 Inokulan Glomus sp. 1 mampu meningkatkan pertumbuhan tinggi dan diameter bibit kihiang sebesar $66 \%$ dan $32 \%$ terhadap kontrol dengan tingkat serapan hara $\mathrm{N}, \mathrm{P}$ dan $\mathrm{K}$ berturut-turut sebesar 49\%,63\%, 62\% terhadap kontrol. Tanaman kihiang umur 6 bulan setelah ditanaman di lapang menunjukkan bahwa inokulan Glomus sp. 2 dan Glomus sp. 3 efektif meningkatkan pertumbuhan tinggi dan diameter kihiang.

\section{B. Saran}

Glomus sp. 2 dan Glomus sp. 3 dapat direkomendasikan untuk diaplikasikan sebagai inokulan FMA dalam produksi bibit tanaman kihiang.

\section{UCAPAN TERIMA KASIH}

Ucapan terima kasih disampaikan kepada para teknisi Laboratorium Mikrobiologi Hutan, Pusat Litbang Hutan, Sugeng Santoso, H. Najmullah, Ahmad Yani, Aryanto dan Herni yang telah membantu penelitian di tingkat persemaian dan pekerjaaan laboratorium. Ucapan yang sama disampaikan kepada Ateb, Masroji, Anwar, Sugeng Santoso, Achmad Yani, H. Najmullah, Aryanto dan Herni Yuniar yang membantu penanaman di lapang dan pengukuran pertumbuhan tanaman.

\section{DAFTAR PUSTAKA}

Abbott, L.K., \& Robson, A.D. (1985). Formation of External Hyphae in Soil By Four Species of Vesicular-Arbuscular Mycorrhizal Fungi. New Phytol 99 : 245-255.
Atul-Nayyar, A. C., K. Hamel, Hanson, and J. Germida. (2009). The Arbuscular Mycorrhizal Symbiosis Links N Mineralization to Plant Demand. Mycorrhiza 19:239-246.

Bing, H., G. Shi-rong, H. Chao-xing, Y. Yan, and Y. Xian-chang. (2012). Effects of Arbuscular Mycorrhiza Fungi (AMF) on the Plant Growth, Fruit Yield and Fruit Quality of Cucumber Under Salt Stress. Chinese Journal of Apllied Ecology. 23 (1) : 154-158.

Binu, N. K., P. K. Ashokan, and M. Balasundaran. (2015). Influence of Different Arbuscular Mycorrhizal Fungi and Shade on Growth of Sandal (Santalum album) Seedlings. J. of Trop. For. Sci. 27 (2) $158-165$.

Budi S. W. and L. Setyaningsih. (2013). Arbuscular Mycorrhizal Fungi and Biochar Improved Early Growth of Neem (Melia azedarach Linn.) Seedling Under Greenhouse Conditions. Jurnal Manajemen Hutan Tropika, 19(2), 103-110.

Cruz, R. E., de la Zarade, J. F., Angganzae, N.S., \& Lorilla, E.B. (1995). Differential Mycorrhizal Developmnet of Some Agricultural, Horticultural and Forsetry Crops to Inoculation of Mycorrhizal Fungi.

Fan, L., Dalpé, Y., Fang, C., Dubé, C. \& Khanizadeh, S. (2011). Influence of Arbuscular Mycorrhizae on Biomass and Root Morphology of Selected Strawberry Cultivars under Salt Stress. Botany, 89, 397-403.

Giovannetti, M., \& Mosse, B. (1980). An evaluation of techniques for measuring vesiculararbuscular mycorrhizal infection in Roots. New Phytol, 84, 489-500.

Gryndler M., Hrselova, H., Sudova, R., Gryndlerova, H., \& Kubat, J. (2006). Organic and mineral fertlization, respectively, increase and decrease the development of external mycellium of Arbuscular Mycorrhizal Fungi in a Long-Term Field Experiment. Mycorrhiza ,16, 159-166.

Hage-Ahmed, K., Krammer, \& J., Steinkellner, S. (2013). The Intercropping Partner Affects Arbuscular Mycorrhizal Fungi and Fusarium oxysporum f. sp. lycopersici Interactions in Tomato. Mycorrhiza, 23, 543-550.

Halder, M., Dhar, P.P., Mujib, A.S.M., Khan, M.S., Joardar, J.C., \& Akhter, S. (2015). Effect of Arbuscular Mycorrhiza Fungi Inoculation on Growth and Uptake of Mineral Nutrition in Ipomoea aquatic. Current World Environmnet, $10(1), 67-75$.

Heyne, K. (1987). Tumbuhan Berguna Indoinesia II. Jakarta: Badan Litbang Kehutanan. Departemen Kehutanan. 
Huang, J.H., Tan, J.F., Hong, J.I.E., \& Ren, Z. (2011). Effects of Inoculating Arbuscular Mycorrhizal Fungi on Artemisia annua Growth and Its Officinal Components. Chin. J. Appl. Ecol., 22(6), 1443-1449.

Irianto, R.S.B. (2015a). Fungi mikoriza arbusklar meningkatkan pertumbuhan awal Aquilaria crassna Pierre ex Lecomte di persemaian dan lapang. Submitted to Jurnal Penelitian Hutan dan Konservasi Alam.

Irianto, R.S.B. (2015b). Efektifitas fungi mikoriza arbuskular terhadap pertumbuhan pulai hitam (Alstonia angustiloba Miq.) di pesermaian dan lapang. Submitted to Jurnal Penelitian Hutan dan Konservasi Alam.

Irianto, R.S.B. (2015c). Pengaruh inokulasi fungi mikoriza arbuskula terhadap pertumbuhan bibit tanaman suren (Toona sureni Merr) dalam Menunjang Keberhasilan Konservasi Ex-situ. J. Forest and Nature Conservation Research, 11(3), 315-323.

Irianto, R.S.B. (2009d). The effect of arbuscular mycorrhizal fungi and slow release fertilizer on the growth of Alstonia scholaris in the Nursery. J. For. Res., 6(2), 139-147.

Jakobsen, I., Abbott, L.K., \& Robson, A.D. (1992). External hyphae of vesicular-arbuscular mycorrhizal fungi associated with Trifolium subterraneum L. : 1. Spread of Hyphae and Phosphorus in Flow into Roots. New Phytol., (120), 371-380

Khade, W.S., \& Rodrigues, B.F. (2009). Studies on arbuscular mycorrhisation of papaya. African Crop Science Journal, 17 (3), 155-165.

Kim, K., Yim, W., Trivedi, P., Madhaiyan, M., Boruah, H.P.D., Islam, R., Lee, G., \& Sa, T. (2010). Synergistic effects of Inoculating Arbuscular Mycorrhizal Fungi and Methylobacterium oryzae Strains on Growth and Nutrient Uptake of Red Pepper (Capsicum annuum L.). Plant Soil, 327, 429-440.

Kementerian Kehutanan. (2014). Statistik Kawasan Huan 2013. Direktur Jenderal Planologi, Kementerian Kehutanan. 115p.

Kobra, N., Jalil, K., \& Youbert, G. (2009). Effects of three Glomus species as biocontrol agents against verticillium-induced wilt in cotton. Journal of Plant Protection Research, 49(2), 185-189.

Larsen, J., Graham, J.H., Cubero, J., \& Ravnskov, S. (2012). Biocontrol Traits of Plant Growth Suppressive Arbuscular Mycorrhizal Fungi Against Root Rot in Tomato Caused by Pythium aphanidermatum. Eur J Plant Pathol, 133, 361-369.
Neumann, E., \& George, E. (2005). Extraction of extraradical arbuscular mycorrhizal mycelium from compartments filled with soil and glass beads. Mycorrhiza ,15 (7), 533-537.

Plenchette, C., Fortin, J.A., Furlan, V. (1983). Growth responses of several plant species to mycorrhizae in a soil of moderate P-Fertility. I. Mycorrhizal Dependency Under Field Conditions. Plant and Soil, 70 (2), 199-209.

Sall, J., Creighton, L., \& Lehman, A. (2005). JMP Start Statistic $2^{\text {nd }}$. A Guide to Statistics and Data Analysis Using JMP and JMP IN Software.

Setiadi, Y. 1999. Status penelitian dan pemanfaatan cendawan mikoriza arbuskula dan rhizobium untuk merehabilitasi lahan terdegradasi. Seminar Nasional Mikoriza I, 15-16 November 1999.

Siddiqui, M.H. (1989). Nodulation study of a few legume tree species during seedling stage. In. Treacy, M and Brewbaker, J. L. (eds). Proc. Nitrogen Fixing Tree Research Reports. The NFTA. USA.

Syamsuwida, D. (2006). Teknik pengadaan benih dan bibit jenis kihiang (Albizia procera Benth.) untuk pengembangan hutan rakyat. Prosiding seminar benih untuk rakyat: Menghasilkan dan Menggunakan Benih Bermutu Secara Mandiri. Bogor, 4 Desember 2006.

Turjaman, M., Y. Tamai, E. Santoso, M. Osaki and K. Tawaraya. (2006). Arbuscular Mycorrhizal Fungi Increased Early Growth of Two Non Timber Forest Product Species Dyera polyphylla and Aquilaria filaria Under Greenhouse Conditions. Mycorrhiza 16: 459-464.

Turjaman, M., Tamai, Y., Sitepu, I.R., Santoso, E., Osaki, M., Tawaraya, K. (2008). Improvement of early growth of two tropical peat-swamp forest tree species Ploiarium alternifolium and Calophyllum hosei by Two Arbuscular Mycorrhizal Fungi Under Greenhouse Conditions. New Forests, 36 (1), 1-12.

Valarini P.J., Curaqueo, G., Seguel, A., Manzano, K., Rubio, R., Cornejo, P., \& Botie, F. (2009). Effect of compost application on some properties of avolcanic soil from Central South Chile. Chilean J. Agric Res, 69 (3), 416-425.

Whitmore, T.C., \& Tantra, I.G.M. (1986). Tree flora of Indonesia. Check List for Sumatera. Bogor: Forest Research and Development Centre.

Wulandari, D., Saridi, Cheng, W., \& Tawaraya, K. (2014). Mycorrhizal colonization enhanced early growth of Mallotus paniculatus and Albizia saman under nursery conditions in East Kalimantan, Indonesia. International Journal of Forestry Research, 2014, 1-8. 